\title{
Kindergarten Children and Language Learning: Missing Pillars for Language Acquisition
}

\author{
Salwa Al-Darwish ${ }^{1}$ \\ ${ }^{1}$ Public Authority for Applied Education \& Training, College of Basic Education, Al Safat PO Box 276 Kuwait \\ 13003 \\ Correspondence: Salwa Al-Darwish, Public Authority for Applied Education \& Training, College of Basic Education, \\ Al Safat PO Box 276 Kuwait 13003. Tel: 965-9901-3946 Fax: 965-2562-1213 E-mail: salwaaldarwish@hotmail.com \\ Received: November 29, 2012 \\ Accepted: December 19, 2012 \\ Online Published: January 7, 2013 \\ doi:10.5430/ijhe.v2n1p44 \\ URL: http://dx.doi.org/10.5430/ijhe.v2n1p44
}

\begin{abstract}
This study examines the perceptions of the Kuwaiti kindergarten school teachers and parents as well as the English curriculum in an attempt to identify areas that need to be improved in the kindergarten teachers' program at the CBE (College of Basic Education). In addition, the paper looks closely into the delivery of information and sequence of interaction in relation to the learning process of English as a foreign language in kindergarten stage in Kuwait. The participants were 12 kindergarten teachers who speak Arabic as their first language and have no experience or knowledge in teaching or speaking the target language, English. The data was collected through the school year 2010/2011 by using observation, interviews and artifacts. The present study implication is that the kindergarten teacher who is teaching the English language without any educational training needs to know English language curriculum, real communication skills and innovation in the classroom, and be competent in teaching English language to kindergarten students.
\end{abstract}

Keywords: Kindergarten, EFL, Curriculum, Teaching, Kuwait, Training

\section{Introduction}

Although children develop skills in reading, writing and oral language (listening and speaking) at an early age, oral language must be the foundation of English as a foreign language (EFL) in the kindergarten learning program. That is being said, a child whose first language is not English would have difficulties to understand, and in return it would have disadvantages on the child. This is true with the case of Kuwaiti kindergarten public schools. While it takes time and conversation-rich environments to learn a new language, learning the new language is very much like learning a first language (Samway \& McKeon, 1999). To learn a new language, there must be opportunities to communicate about real things and events. Children need places inside and outside the classroom to practice their new language where errors are accepted and recognized as part of the process of acquiring English. These kindergarten children need certain conditions which are determined with respect to the building and curricula as well as the teaching methods. Therefore, there is no more any traditional method suitable for the children, and neither is there any traditional teacher fit to teach them; specific qualifications have been agreed on internationally. The teacher should be qualified academically in order to meet the children's wishes and needs; she should be endowed with a positive personality in dealing with them. Thus, she would be able to develop and advance the standard of the children's capabilities and creativity; she would also attain a higher standard in their knowledge acquisition and build harmonious characters endowed with a high self- concept.

\section{The Problem}

From 2009 on, the Kuwaiti Ministry of Education (MOE) has introduced English as a compulsory subject in the public kindergarten school curriculum. The decision to teach English in kindergarten schools was taken without any prior field study into the positive or negative effects that might result. An example of the haste with which it was implemented was the use of the English textbook designed and directed by the Ministry of Education-Curricula Development Department without any revision implemented on the content of the book. The assigned text book for kindergarten level and the associated English curriculum are based on two language methodologies, the Total Physical Response method and the communicative approach. Thus, they introduced kindergarten children to a method in which they memorize vocabulary, practice them orally, and then use them in some writing exercises and 
activities. This was at a time when teacher preparation for teaching English at higher levels emphasized natural communication.

With this hasty decision to teach English at the kindergarten stage came the decision of allowing the same kindergarten teachers to teach English language to these children even though they have no knowledge and experience in the language itself. Furthermore, these Kuwaiti kindergarten teachers who taught in this stage were only trained in the kindergarten curriculum and were graduates with bachelors' degrees in kindergarten teaching from the College of Basic Education.

\section{Significance of the Study}

Teacher training for kindergarten school and the teaching of English as a foreign language in Kuwait are offered by the College of Basic Education (CBE), a college that trains and graduates teachers mainly for kindergarten and primary levels, and which therefore did not prepare them to teach English before 2009 until now. After the English language was implemented at the kindergarten level in 2009, the Ministry of Education (MOE) and the CBE started working closely together to develop a training program for kindergarten teachers with an emphasis on teaching English as a foreign language; however, English language is being taught to kindergarten children by teachers without experience in teaching oral language; they lack the ability to identify and manipulate phonemes, build vocabulary, develop awareness of meaning and develop awareness of the target language structure, and hence they have no ability to develop the foundation for reading and writing.

It is very difficult to explain how the kindergarten teachers holding only a degree in teaching kindergarten children who are trying to carry out these changes view their effects on the students. Therefore, there is a need to investigate how these mixed techniques and changing curricula are in fact being taught, and what changes teachers themselves would like to effect in the curriculum and methodology and in teacher training by the Department of Kindergarten at the CBE. The author is also interested in understanding exactly how these kindergarten teachers carry on the English curriculum without any prior knowledge in the target language.

\section{Research Questions}

In this study, questions were constructed to reveal not only the teachers instructional practices but also to learn about the principles that guided the teachers' and parents' beliefs and support for implementing the English language curriculum. Therefore, this study is intended to answer the following questions:

$$
\text { What are the teachers' perceptions of implementing the English language curriculum in kindergarten stage? }
$$

What are the kindergarten parents' perceptions about the English language curriculum?

\section{Kuwaiti Kindergarten curriculum}

The kindergarten program focuses on the areas in general philosophy; philosophy of the Society of Kuwait; and philosophy of the Kindergarten level. These areas illustrate in details the modern trends in pre-school child education, the philosophy at kindergarten level in Kuwait, the criteria for the effectiveness of the objectives, the classification of the objectives and their different levels, the general objectives for kindergarten children who are between 3 and 6 , and the characteristics of the development in early childhood which covers in its turn sensor-motor physical development, the cognitive development, and the socio-emotional development. Furthermore, the medium of instruction is Arabic. Some examples of the linguistic concepts for level one are: experience of who I am, experience of my family, relatives and neighbors; experience of my health and safety; experience of water and air; experience of animals and plants; experience of sounds, forms and colors; experience of my homeland, Kuwait; experience of transportation (desert and sea); and finally some applications related to the supermarket (English textbook, 2009).

\section{Kindergarten program at $\mathrm{CBE}$}

The kindergarten program in the CBE focuses on three areas. The first one consists of oral communication, writing skills in Arabic which is students' first language, and the intellectual skills in understanding and appreciating the Arab and Islamic culture. The second area comprises the knowledge and skills of pedagogy in kindergarten stage. The third area which is the major requirement and covers the conceptual knowledge of different educational curriculum such as sustainable, environmental, educational citizenship, kindergarten school math and science, kinetic and musical, child nutrition, child literature in Arabic, psychology, and kindergarten workshop.

\section{English language program at $\mathrm{CBE}$}

The English Language Program in the CBE focuses on three areas. The first consists of the knowledge and skills needed to be a competent teacher of English language and culture, including communicative competence in speaking, 
listening, reading, and writing. The second area comprises the knowledge and skills of pedagogy. The third area covers conceptual knowledge of English (Course Description Catalogue, 2000).

\section{Theoretical Framework}

It has been claimed that foreign language learning should start in the primary years (Cameron, 2008). However, teaching kindergarten children could be considered an extension of mothering rather than as an intellectual enterprise (Cameron, 2008). So, when children first learn their home language, they begin as infants to produce all the phonemes necessary to be a speaker of that language (Adams, et al, 1999). Adams added that between ages 1 and 3 years, children acquire about 1,000 to 3,000 words and start to form simple forms, often one-word, and then sentences. From ages 3 to 5 years, they start to play with language and become aware of rhymes and phonological aspects of language such as words that begin with the same sound. From 5 to about 8 years they learn more sophisticated vocabulary and complex structures of the home language (Geva \& Petrulis-Wright, 1999). With this development in mind, now what must a child do to add a new language to this rich language base in his or her home language upon entry to school? Language does have important elements, some more formal than others (Richgels, 2005). Richgels (2005) describes the formal elements of a language as phonology, morphology, semantics, and syntax, whereas the informal elements of the language are paralinguistic which involves learning about signs, gestures, and facial expressions that parallel language production. The functions of language were described by Halliday (1975) and they include: Instrumental—Expression of needs and wants, Regulatory—Regulation of others' behavior, Interactional- interaction with others, Personal-Expression of opinions or feelings, Imaginative - Imagination, Heuristic - Inquiry, and Representational-Information; and finally, conversation or discourse when children need to understand how to engage in conversations with peers and with teachers. In addition, they learn to observe the language of school and to participate in conversations with the language capabilities they have.

For as long as students have shown differences in backgrounds, talents, and interests, effective teachers have instinctively tailored methods and materials to accommodate those differences (Ong and Murugesan, 2007). Creative teachers have purposefully crafted instructional menus that cater to the many learning appetites in any one classroom (Middendorf, 2008). While teachers make a difference in the ease with which students come to learn English, in classrooms where there is space for conversations, both social and academic, students tend to become more adept in English (Bartolome, 1998; Gutiérrez, 1995).

As a compelling body of evidence exists about the knowledge and skills that kindergarten teachers must possess (Kagan, Kauerz \& Tarrant, 2008; Shore, 2009b), generally speaking, these teachers are most effective when they are trained to understand - and be prepared to put into practice their knowledge about — child development, diverse learning styles, social and emotional development, cultural diversity, successful teaching strategies, SL/FL language methodologies, and engaging families (Carter \& Nunan, 2007). Unfortunately, the formal education and certification required of Kindergarten teachers, as well as the professional development provided to them, especially if we are speaking with regard to the teaching of the English language, rarely reflect the support of the kindergarten children's learning and development in the English language. That is because an important dimension of classroom interaction is the teacher questions and when teachers fail to elicit any response from the learners, then they need to modify their questions (Carter \& Nunan, 2007). The teacher's awareness of the target language is vital for improving pedagogical practice, especially if she needs to include the syntactic and semantic modifications.

However, an important distinction should be made between second language learning and foreign language learning. A second language is "one that is learned in a location where that language is typically used as the main vehicle of everyday communication for most people" (Zare, 2012). The second language context provides constant visual and auditory stimulation in the target language. However, if second language learners are surrounded by informal or incorrect models of the language they are learning, emphasis on grammar will be especially important to make them aware of formal, correct speech as well as informal dialects.

By contrast, a foreign language is "one that is learned in a place where that language is not typically used as a medium of ordinary communication" (Zare, 2012). Foreign language learners are at a disadvantage because their own native language surrounds them. The foreign language student typically receives input from the target language only in the classroom setting and lacks the opportunity of a second language learner to practice the target language on a daily basis. Much heavier emphasis on pronunciation, intonation, and informal usages is needed with foreign language learners than with second language learners if they are to learn to speak the language fluently. According to Curtain and Pesola (1994) and Tedick and Walker (1995), one of the factors that make the teaching of foreign languages especially challenging is that teachers must maintain proficiency in the target language and stay up to date 
on current issues related to the culture of the target language. Regardless of the skills and knowledge that foreign language teachers possess when they commence teaching, maintenance and improvement must be an ongoing process.

Freeman (1998) indicated that in order for learning to be meaningful and have a clear purpose, an assignment or activity should stem from the teacher's understanding of the students' needs and must be understood by the students. Moreover, research shows that teachers who regularly participate in collaborative professional development positively impact child outcomes (Brown \& Bogard, 2007).

To achieve the best outcomes, the quality of the teachers who are teaching English language in Kindergarten matters because kindergarten is a world unto itself, where the learning is in the process (Middendorf, 2008). Generally, the factors that have long-term impact on children's achievement include both the social interactions in classrooms and the quantity and quality of literacy and math instruction (Pianta, Belsky, Vandergrift, Houts \& Morrison, 2008). These variables relate to how much instruction occurs and in what setting, how teachers interact with children, and overall classroom qualities such as the emotional climate. Unfortunately, there is increasing evidence that the quality of Kindergarten classrooms, specifically (Pianta, LaParo, Payne, Cox \& Bradley, 2002), is widely variable at best.

More than any other primary grade, kindergarten teachers must inspire a love of learning, a can-do feelings in each child, and an eagerness to take a risk (Middendorf, 2008). Although time to converse is important, teachers also adapt their own language patterns. They speak slower, use shorter sentences, paraphrase and share a message in several ways, and explain word meanings. They also use gestures, pictures, and objects to make the meaning of their message clear. They avoid idioms as they are difficult for ELLs to understand. Teachers become aware of the language expectations of a lesson as well as its content expectations (Echevarria, Vogt, \& Short, 2004).

Harold Palmer, the prominent British applied linguist, summarized some general principles of language teaching methodology in the 1920s. These concerns are reflected in most of the specific methods described below, and remain useful as a guide to teachers regardless of the method being used: (1) initial preparation (orienting the students towards language learning); (2) habit forming (establishing correct habits); (3) accuracy (avoiding inaccurate language); (4) gradation (each stage prepares the student for the next); (5) proportion (each aspect of language is given emphasis); (6) concreteness (movement from the concrete to the abstract); (7) interest (arousing the student's interest at all times); (8) order of progression (hearing before speaking, and both before writing); (9) multiple lines of approach (using many different ways to teach the language (Richards, 2001).

Clearly, completing an undergraduate major is not sufficient to teach everything that a teacher of English as a foreign language needs to know. According to Brown (2000), it is not obvious that knowledge taught in academic disciplines at the college level is even necessarily relevant to the content covered in the schools. According to Schrier (1994), the knowledge base in foreign language education is the central issue in teacher training. This covers understanding the content areas students have been prepared in, understanding how that preparation should be reflected in their teaching assignments, and what they need for their own professional growth. Wilson (1987) suggests that teachers should know (1) the facts, how to organize them, and the basic concepts that they are to teach; and (2) how to transform complex academic knowledge into subjects that can be taught easily. As if that isn't enough of a challenge, kindergarten teachers must also teach all the concepts of literacy and math that will be the solid foundation for future success. In addition, they must do it all while respecting individual differences among all the children in the classroom (Middendorf, 2008).

\section{Methodology}

\subsection{Approach.}

The study was carried out over the fall semester of 2011. It was designed as a qualitative study with a multi-method focus (Richards, 2003): non-participant observation in the classroom; individual interviews with teachers, individual interviews with parents, and analysis of artifacts such as textbooks, workbooks, teachers' guides, and visual and aural aids.

\subsection{Setting and participants.}

The research sites for this study were twelve kindergarten classrooms in all six of the school districts in Kuwait. A single kindergarten school within each district was selected for this study by the author. Two kindergarten teachers in each school were chosen by the school authorities. After getting permission from the Ministry of Education, the author got the approval from two teachers in each school to be observed and interviewed. Each teacher was observed for an hour three times a week for three months. A total of thirty six hours of observation for each teacher was carried out. 
It should be explained that in Kuwaiti kindergarten schools, there are level one and level two kindergartens. In each classroom, there are the main classroom teacher and her assistant. Both, their first language is Arabic and the medium of instruction inside the classroom is carried out in Arabic as well, except for the period which is devoted for the English language curriculum. Furthermore, there are no important ethnic divisions in Kuwait, as the students' population is overwhelmingly Arab, and there is a strong sense of national identity. However, two distinct cultural communities, with different dialects, can be distinguished: people who are originally from the capital, Kuwait City, and are called the Hadhar, and people originally from the desert or remote towns and villages, called the Bedouin (Hussein, 1960).

After the observation period, each teacher provided an individual interview with the researcher in the school, lasting for about an hour to an hour and a quarter. The language used in the interviews was mainly Arabic. Participants in the study were reminded that the information they were sharing was confidential. The interviews were all tape-recorded and transcribed by the researcher, and the transcripts were checked for accuracy by the interviewees. The researcher also had brief, informal interviews with some parents. At the end of the research period, the researcher gave each teacher a chance to read a preliminary draft of her case and comment on whether the researcher's description of her views and teaching approach accurately mirrored her understanding of it. The researcher examined artifacts such as teachers' guides and visual aids throughout the research period.

\subsection{Limitations of the study.}

There were many limitations to the present study. First, the presence of the observer in the classroom may have made teachers nervous and cautious about innovating. Secondly, teachers may have hesitated to give frank answers in the one-on-one interviews for fear they might be reported to the Ministry. Thirdly, the findings of this study cannot even be generalized because it was applied only to public kindergarten school teachers who were Kuwaitis, as private kindergarten and foreign teachers were not studied. However, the striking similarities in practice and attitudes across the six districts that were studied, and that were chosen to represent different social diversity, suggest that the findings can be applied across all six Kuwaiti school districts.

\section{Data Analysis}

The analysis of classroom observations, interviews, and artifacts identified four themes. These themes had major effects for the topic of this paper: (1) Teachers' and parents' dissatisfaction with the curriculum; (2) The lack of real communication, spontaneity, and innovation in the classroom; (3) Cultural awareness; and (4) Teachers' dissatisfaction with their educational training.

Validity was checked using triangulation. The same questions were asked of teachers, and parents. Also, the same questions were asked of different types of data, such as observational field notes, audio and video recordings of classes, individual interviews, teachers' lesson plans and supplementary worksheets, the textbook, and the teachers' manual. Thus, the themes that were finally developed represented multiple sources and informants.

\section{Interpretation of the data}

\subsection{Teachers and parents' dissatisfaction with the curriculum.}

There was evidence from several sources that teachers were uncomfortable at being observed, and in some cases they may have followed the curriculum more rigidly, taking fewer risks and innovating less, especially when parents and other MOE administrators were observing them. However, the main effect of observation seems to have been that some teachers took care to be better prepared and followed the textbook than others. The kindergarten classes that were observed were based on the lessons laid out in the teachers' guides, which reflected the traditional communicative approach of Kuwaiti English education. For example, the teachers' guide (page 135-138) consists of a table divided into two columns with the entire daily language classroom that should be used by the teachers, such as "Good morning" in one column and opposite to it in Arabic "sabah Al kheer".

Furthermore, the classes consisted of vocabulary drills, exercises, and games. Classes always started with a ritual of greeting: "Good morning, children! Good morning, teacher! How are you? I'm fine, thank you?" Teachers then presented pictures of vocabulary items on flash cards or realia, or more rarely, made gestures, such as waving their hands, and asked, "What is this?" The class would call out the answer, such as "It's a hand." After the children had practiced a new item a few times, the teachers went on repeating more and more without checking whether most children had learned the new material. The same vocabulary would be presented again over several weeks, with variations in the type of drill. 
Classes typically ended with games (such as playing with the sand to form the vocabulary word they have been drilling on, or listening to recorded English songs and singing along with them, or workbook exercises). A typical exercise might involve making a circle around a picture when the teacher calls out its correct name. For example, the handout distributed among the children with two pictures of a school bus and one picture of a hand and then the teacher calls on the word "hand". The teachers' guide encouraged teachers to have children review vocabulary and play games in small groups or pairs, but this was not observed; mainly all class was doing the activity. The reason behind this procedure was the teachers were concerned about losing control of their classes. The children often clearly enjoyed the songs, which enabled them to have fun and feel more involved with English. However, the teachers did not sing as the manual noted the importance of songs, because they could not model native stress, intonation, and pronunciation. So, unfortunately, the quality of the audio recordings was poor, and teachers sometimes ended up silent.

Children's mistakes were often not corrected, but instead ignored, because not only teachers didn't realize these mistakes, such as pronouncing "rike" for "rice", "lean" for "lion" and "blane" for "plane" but also so as not to discourage or humiliate the children, in accord with instructions in the teachers' guide. Later, the teacher or another child might model the correct answer.

The English alphabet, reading, and writing were not included in the curriculum at this early stage, and English vocabulary was learned entirely by listening and speaking (parroting). By the end of the second semester, in May, first level kindergarten children were supposed to have copied or traced both the English numbers (1-10) and the English upper and lower cases (S, H, M, B, W, L, Y, R, K, P, G and F alphabets), but words were not presented, and thus English writing from left to right was not introduced.

The teachers' manual encourages teachers to innovate beyond the lesson plans that are laid out, and suggests activities that promote student interest and communication, such as pair work and games. The manual says, "With a little imagination, the possibilities are endless." It also says, "In the lesson notes, there are suggestions on how to use the pupil's activity book in particular lessons. These notes may help the teacher who has some command of the target language. However, the illiterate English language teacher should feel apprehensive to exploit them in any way she wishes."

Conversely, the manual also lays out a series of lesson plan for each of the twelve vocabulary words in each unit in the textbook. It is possible to teach for an entire year simply by following these plans. Throughout the period of my observation, illiterate and literate teachers followed these lessons, mostly without any deviation, like actors following a script because it was all in the Arabic language apart from the alphabet and the vocabulary word that represents it. On the contrary, the few cases of innovation that were observed suggested that perhaps this was due to some assurance they had with the experience of traveling abroad to countries where the target language is used. One teacher in particular, Dalal, occasionally departed from the lockstep lesson plans by innovating activities that were adapted to the students' interests. In one class, Dalal showed her kindergarten children a bowl filled with water and let them dip their hands in it, trying to teach "water" and "hand."

In the interviews, the kindergarten teachers reported that the ministry norms and values supported a hidden goal of teaching toward future usage of the language in primary stages. They felt caught in a dilemma between the official requirement to emphasize listening and speaking and the knowledge that these children would be expected to begin taking examinations in reading and writing when they reached third grade. Since the teachers would be held accountable if the children did not do well in primary stages, they had an interest in trying to introduce a little more formal work in the kindergarten level than the official curriculum encouraged. For example, some teachers were taking the initiative of coaching the children with some vocabulary words from the curriculum by giving each child a small board and chalks to write, whereas the official book concentrates only on tracing the dotted lines from left to right for writing in the target language while in the Arabic language students write from right to left.

All teachers regarded student motivation as a critical problem, which they believed often reflected parental attitudes toward the English curriculum. Some parents disapproved of children learning foreign languages at all, and the researcher's interviews with parents in one district confirmed this. However, the parents believed that the decision by the Ministry of Education to carry on with executing the English curriculum in first year kindergarten has caused seriously a large problem for children not to desire to attend school. One parent's remark was as follows:" At this stage when we are talking about kindergarten, children are still young and learning should be fun, fun, fun." Another comment was:" These are children and it is better for them to work at their own pace so that they don't grow to hate going to school." It was also suggested that some parents especially the high class ones did not see the value of learning to speak and listen without learning to read and write. 


\subsection{The lack of real communication, spontaneity, and innovation in the classroom.}

It is naturally difficult to achieve genuine, active communication among children who do not yet know a language with their teacher. Using the small number of vocabulary items the children have learned through interactive games and exercises offers the most potential impact for language acquisition. But the exercises that were observed in these classrooms were almost never very communicative. There was little freedom or lack of predictability in what teachers and children did or said. The teachers were in control of the activities, and the children parroted the teachers' sentences. The teachers often turned to a new activity without making sure that the children understood what they had just been saying. The teachers' recitation and discussion questions were narrow, memorized and drill-oriented, and did not encourage anything other than passive repetition.

Not only the children, but the teachers were passive and limited in what they did. In these twelve classrooms in different cultural areas, under teachers with different personalities and ideas, the researcher observed identical classes, which might have been photocopies of each other. They were indeed photocopies - or at least represented the same pages of the teacher's manual. The overriding goal of these teachers seemed to complete the step-by-step, class-by-class plan supplied by the Ministry of Education, regardless of whether they thought the children understood or even themselves. Keeping pace with the other teachers seemed to be a major priority.

Classes were carried out largely in English. The teachers' guide warned against falling into the temptation of using Arabic in the classroom, even though the lesson plans in the guide were all in first language, in discrepancy with the communicative approach. However, the guide did advise teachers to translate the vocabulary being taught if children did not understand. One teacher in particular, Amena, usually used only her first language, Arabic, in class in order to bring all the children along, either in their understanding or in doing an exercise or game correctly except for the vocabulary item of the week which she uttered it in English. This had the effect of keeping up the momentum of the class.

The officials at the Ministry of Education thought teaching the English language to these children would help them later in their lives. One teacher stated: "Look at us. In the past, the English language was taught to us only at the intermediate and high school levels, but see how far we've come: some of us majored in Kindergarten just to get away from English and ended up teaching it."

\subsection{Cultural awareness.}

An important element of a communicative curriculum that was conspicuously absent here was information about the cultures of the countries in which English is spoken. The English songs the children heard and at least partially learned concerned topics in Kuwaiti culture rather than English culture. Teachers might perhaps have supplied the deficit with pictures or other material from the internet, magazines, newspapers, children's books, or English nursery rhymes or stories. The absence of this material may be in deference to the hostility of some parents to teaching foreign culture in Kuwaiti schools. The researcher confirmed the presence of this attitude through an informal interview of parents in a district with a fairly high Bedouin population. The author's interviews with parents showed that they tended to have little interest in English language teaching at any level of education. Furthermore, most parents stated that they prefer their children to get degrees in majors that require little or no foreign language knowledge, such as Law, Religious Studies, or the Humanities.

\subsection{Teachers' dissatisfaction with their educational training.}

All twelve kindergarten teachers conveyed insecurity about their level of English proficiency, especially in the realm of speaking and listening. They were dissatisfied with the only two English courses which didn't prepare them to teach the target language. One teacher claimed that "In the MOE everything gets messed up and we, the teachers, get blamed for it.... Do you think two general English courses during our bachelor's degree are enough and qualify us to teach these kids the language?" Another teacher reacted strongly: "The fun of kindergarten is gone. This is all due to implementing the English language in the kindergarten curriculum. It's all really very sad and depressing".

All twelve teachers occasionally made errors in English pronunciation, intonation, and grammar in the classroom, even though they were repeating very simple sentences from the official lesson plans. The researcher recorded remarks such as "This is a water" (for "this is water"), "What do you can say?" "How are today?" (for "How are you today," a ritual greeting at the beginning of each class) "let its trace the dots." "What is its number?" It is difficult to know to what extent these mistakes were due to nervousness at the presence of the observer. This is clearly problematic for a communicative curriculum. 


\section{Conclusion}

Much has been done in the last decade and a half to meet the demand for English teaching in Kuwait, but more has to be done to ensure quality teaching and learning in the kindergarten classrooms. In observing these classrooms, the researcher constantly felt a sense of opportunities missed, which mirrored the teachers' conviction that they were not giving the children as much knowledge as they wanted to give. The kindergarten curriculum left out most of the elements of foreign language teaching that are found around the world, such as translation, grammar, reading, writing, spelling, and dictation (Richards, 2002). Teaching all four language skills together is widely regarded as preferable to other approaches, as the same material is reinforced when it is learned in different modes.

The Ministry of Education should relax its curriculum guidelines so that creative teachers can feel free to do their best teaching. The official curriculum has not served as a framework of goals, within which teachers may develop their own teaching styles, but instead has been functioning as a straitjacket, imposing unimaginative, curriculum-centered teaching. Instead of laying out lesson plans for the entire year, the teachers' manual might set learning goals, and then offer a rich array of teaching techniques and materials for teachers to choose in developing their own lesson plans.

Because of the emphasis in the curriculum on learning from context, the teachers were reluctant to translate, and, therefore, some children did not seem to be learning the meanings of the core vocabulary. Teaching meanings from context alone without translating tended to confuse children and seemed unnecessarily slow and artificial. The teachers were frustrated to conduct classes entirely in English and thought it was unrealistic with beginning students who did not hear English spoken outside their one English classroom. The classroom did not offer the variety of situations that a natural speech environment would offer, nor did children have the same intense motivation that first language learners would have to imitate the speech of their caregivers.

The kindergarten teachers did not have the fluency or the confidence of native speakers, and, in fact, they modeled grammatical errors, even in repeating the simple sentences in the official lesson plans. They also did not model native speaker pronunciation, and the audio cassettes of songs that accompanied the textbooks were poorly recorded and hard to understand. These deficiencies raise additional questions about the overwhelming emphasis on speaking and listening in this curriculum. As Li's (1998) rightly commented: "The deficiency in spoken English apparently prevented some teachers from applying CLT, but, for others, lack of confidence was more likely to have been the reason" (p. 686).

\section{References}

[Online] Available: www.edu.gov.on.ca/eng/curriculum/.../kindergarten.html.

Adams, M., Foorman, B., Lundberg, I., and Beeler, T. (1999). Phonemic awareness in young children: A classroom curriculum. Baltimore: Paul H Brooks Publishing Co.

Bartolome, L. (1998). The misteaching of academic discourses: The politics of language in the classroom. Boulder: Westview Press.

Brown, B. \& Bogard, K. (2007). Pre-kindergarten to 3rd grade (PK-3) school-based resources and third grade outcomes. Washington: Child Trends.

Brown, H. Douglas. (2000). Principles of language learning and teaching. (4 ${ }^{\text {th }}$ ed.) New York: Addison Wesley Longman, Inc.

Cameron, Lynne. (2008). Teaching languages to young learners. (10 ${ }^{\text {th }}$ ed).Cambridge: Cambridge University Press.

Carter, Ronald, and Nunan, David. (2007). The Cambridge guide to teaching English to speakers of other languages. Cambridge: Cambridge University Press.

College of Basic Education. (2000). Course description catalogue. Kuwait: Public Authority for Applied Education and Training.

Curtain, H. \& Pesola, C. (1994). Languages and children: Making the match (2 ${ }^{\text {nd }}$ ed.). New York: Longman.

Echevarria, J., Vogt, M., \& Short, D. (2004). Making content comprehensible for English language learners: The STOP model ( $2^{\text {nd }}$ ed.) New York: Allyn \& Bacon.

Freeman Y.S., and Freeman, D.E. (1998). ESL/EFL Teaching: Principles for Success. Portsmouth: Heinemann. 
Grva, E., \& Petrulis-Wright, J. (1999). The role of English oral language proficiency in reading development of L1 and L2 primary level children. Unpublished manuscript, Department of Human Development and Applied Psychology. University of Toronto, Ontario, Canada.

Gutierrez, K. (1995). Unpacking academic discourse. Discourse Processes, 19 (1), 21-38. http://dx.doi.org/10.1080/01638539109544903

Halliday, M. S. K. (1975). Learning how to mean. New York: Elsevier.

Hussein, A. (1960). Lectures on the Arab Society in Kuwait. Cairo: Institute for Higher Arab Studies, the Arab League.

Kagan, S.L., Kauerz, K., \& Tarrant, K. (2008). The early care and education teaching workforce: At the fulcrum. New York: Teachers College Press.

Li, D. (1998). It's always more Difficult than you Plan and Imagine: Teachers' Perceived Difficulties in Introducing the Communicative Approach in South Korea. TESOL Quarterly. 32 (4), 677-703. http://dx.doi.org/10.2307/3588000

Middendorf, Cindt. (2008). Differentiating instruction in Kindergarten: Teaching strategies. New York: Scholastic Inc.

Ministry of Education. (2009/2010). Pupils book. Level (1+2). Educational research and curricula sector, Curricula Development Department.

Ong, Fisk, M. and Murugesan, V. (2007). Teaching English to young learners: An illustrated guide for EFL teacher development. San Francisco: Campass Publishing Co.

Pianta, R.C., Belsky, J., Vandergrift, N., Houts, R. \& Morrison, F.J. (2008). Classroom effects on children's achievement trajectories in elementary school. American Educational Research Journal, 45(2), 365-397. http://dx.doi.org/10.3102/0002831207308230

Pianta, R.C., LaParo, K.M., Payne, C., Cox, M.J. \& Bradley, R. (2002). The relation of kindergarten classroom environment to teacher, family, and school characteristics and child outcomes. The Elementary School Journal, 102(3), 225-238. http://dx.doi.org/10.1086/499701

Richards, J.C. (2001). Curriculum development in language teaching. Cambridge: Cambridge University Press. http://dx.doi.org/10.1017/CBO9780511667220

Richards, K. (2003). Qualitative inquiry in TESOL. New York: MacMillan. http://dx.doi.org/10.1057/9780230505056

Samway, K., \& McKeon, D. (1999). Myths and realities: Best practices for language minority students. Portsmouth: Heinemann.

Schrier, L. (1994). Understanding the foreign language teacher education process. ADLF Bulletin, 25, 70-74.

Shore, R. (2009b). PreK-3rd: Teacher Quality Matters. New York: Foundation for Child Development.

Tedick, D., \& Walker, C. (1995). "From Theory to Practice: How we prepare Teachers for Second Language Classrooms." Foreign Language Annals, 28 (4): 499-517. http://dx.doi:10.1111/j.1944-9720.1995.tb00823.

Tichgels, D. (2005). Paying attention to language. Reading Research Quarterly, 39, 470-477. http://dx.doi:10.1598/RRQ.39.4.6

Wilson, S. M. (1987). 150 different ways of knowing: Representations of knowledge in teaching. In Calderhead, J. (Ed), Exploring teachers' thinking. London: Cassel.

Zare, Pezhman. (2012). Language Learning Strategies among EFL/ESL Learners: A Review of Literature. International Journal of Humanities and Social Science, 2 (5), 162. 